\title{
Model Based Biomass System Design of Feedstock Supply Systems For Bioenergy Production
}

\section{IDETC/CIE 2013}

Kara G. Cafferty

David J. Muth, Jr.

Jacob J. Jacobson

Kenneth M. Bryden

The INL is a

U.S. Department of Energy

National Laboratory

operated by

Battelle Energy Alliance

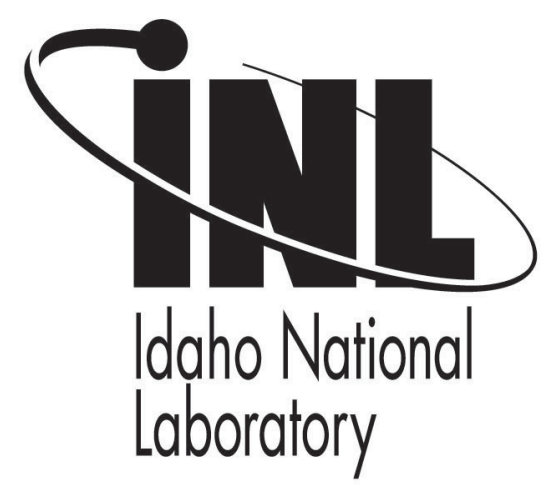

\section{August 2013}

This is a preprint of a paper intended for publication in a journal or proceedings. Since changes may be made before publication, this preprint should not be cited or reproduced without permission of the author. This document was prepared as an account of work sponsored by an agency of the United States Government. Neither the United States Government nor any agency thereof, or any of their employees, makes any warranty, expressed or implied, or assumes any legal liability or responsibility for any third party's use, or the results of such use, of any information, apparatus, product or process disclosed in this report, or represents that its use by such third party would not infringe privately owned rights. The views expressed in this paper are not necessarily those of the United States Government or the sponsoring agency. 


\section{MODEL BASED BIOMASS SYSTEM DESIGN OF FEEDSTOCK SUPPLY SYSTEMS FOR BIOENERGY PRODUCTION}

\author{
Kara G. Cafferty \\ Idaho National Laboratory, U.S. Dept. of Energy \\ Idaho Falls, ID, U.S.A. \\ Jacob J. Jacobson \\ Idaho National Laboratory, U.S. Dept. of Energy \\ Idaho Falls, ID, U.S.A.
}

\author{
David J. Muth Jr. \\ Idaho National Laboratory, U.S. Dept. of Energy \\ Idaho Falls, ID, U.S.A.
}

\author{
Kenneth M. Bryden \\ lowa State University \\ Ames, IA, U.S.A.
}

\begin{abstract}
Engineering feedstock supply systems that deliver affordable, high-quality biomass remains a challenge for the emerging bioenergy industry. Cellulosic biomass is geographically distributed and has diverse physical and chemical properties. Because of this feedstock supply systems that deliver cellulosic biomass resources to biorefineries require integration of a broad set of engineered unit operations. These unit operations include harvest and collection, storage, preprocessing, and transportation processes. Design decisions for each feedstock supply system unit operation impact the engineering design and performance of the other system elements. These interdependencies are further complicated by spatial and temporal variances such as climate conditions and biomass characteristics. This paper develops an integrated model that couples a SQL-based data management engine and systems dynamics models to design and evaluate biomass feedstock supply systems. The integrated model, called the Biomass Logistics Model (BLM), includes a suite of databases that provide 1) engineering performance data for hundreds of equipment systems, 2) spatially explicit labor cost datasets, and 3) local tax and regulation data. The BLM analytic engine is built in the systems dynamics software package Powersim ${ }^{\mathrm{TM}}$. The BLM is designed to work with thermochemical and biochemical based biofuel conversion platforms and accommodates a range of cellulosic biomass types (i.e., herbaceous residues, short- rotation woody and herbaceous energy crops, woody residues, algae, etc.). The BLM simulates the flow of biomass through the entire supply chain, tracking changes in feedstock characteristics (i.e., moisture content, dry matter, ash content, and dry bulk density) as influenced by the various operations in the supply chain. By accounting for all of
\end{abstract}

the equipment that comes into contact with biomass from the point of harvest to the throat of the conversion facility and the change in characteristics, the BLM evaluates economic performance of the engineered system, as well as determining energy consumption and green house gas performance of the design. This paper presents a BLM case study delivering corn stover to produce cellulosic ethanol. The case study utilizes the BLM to model the performance of several feedstock supply system designs. The case study also explores the impact of temporal variations in climate conditions to test the sensitivity of the engineering designs. Results from the case study show that under certain conditions corn stover can be delivered to the cellulosic ethanol biorefinery for $\$ 35 /$ dry ton.

\section{INTRODUCTION}

Engineering feedstock supply systems that deliver affordable high-quality biomass remains a challenge for the emerging bioenergy industry. The focus for the industry has been the development of conventional biomass feedstock supply systems that incorporate existing technologies and equipment with limited engineering and adaptation for dedicated bioenergy feedstock resources and biomass infrastructure $[1,2]$. These system designs can in many cases provide the lowest delivered cost of biomass resources to a biorefinery. However, conventional systems provide limited ability to control critical feedstock quality parameters [3]. Because of this, abrupt variations in feedstock characteristics (i.e. moisture content, ash content, etc) as the result of a drought or other environmental conditions could challenge the economic 


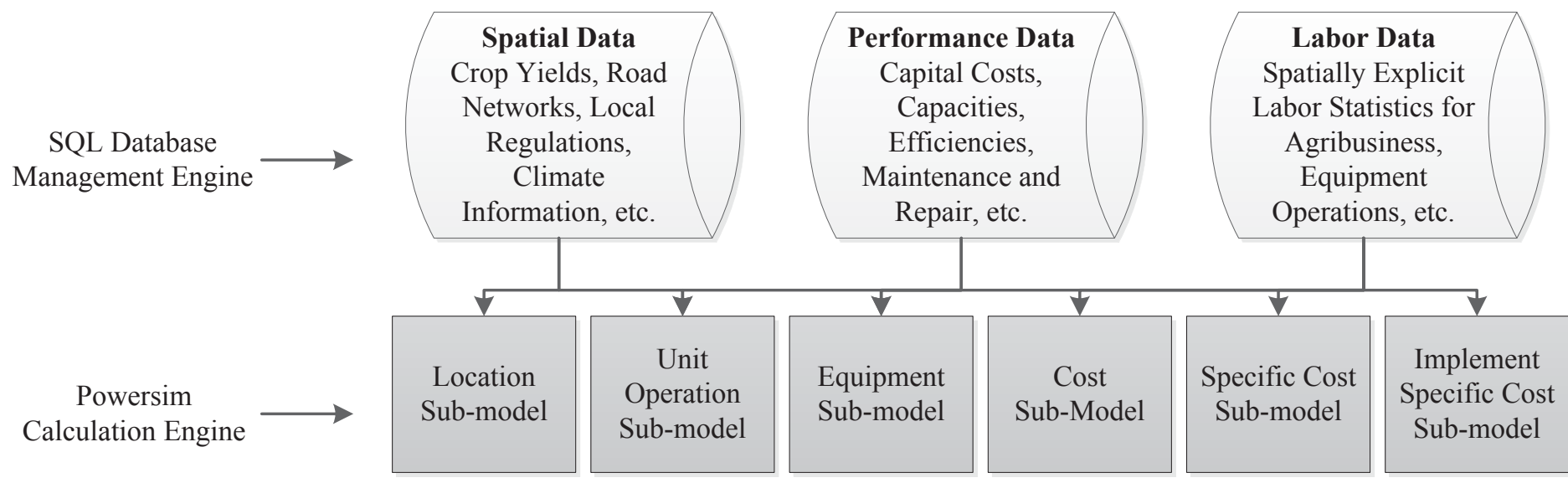

Figure 1. BLM Framework.

viability of a biorefinery. Feedstock supply system design tools that allow decision makers to explore the impacts and sensitivities created by system design decisions are important to support biorefinery investments [4].

Previous work in feedstock supply system modeling involved mathematical programing approaches including linear programming to develop optimization models that are relevant to a variety of cases, but are subject to the availability of data $[5,6,7]$. Additionally, simulation models have also been developed using object oriented programming and discrete event simulation $[8,9,10]$, but tend to generalize operations. This paper develops an integrated model that quantifies the impacts of feedstock supply system designs on the cost and quality of the delivered biomass. The integrated model called the Biomass Logistics Model (BLM) simulates the broad set of parameters required to assess the engineering performance of a supply system design. BLM also allows the user to investigate important sensitivities and uncertainties that are currently a primary source of feedstock risk for the emerging biorefining industry.

\section{METHODOLOGY}

\section{Biomass Logistics Model Description}

The Biomass Logistics Model was developed by the Idaho National Laboratory (INL) to estimate delivered feedstock cost and energy consumed for biomass feedstock supply systems. The model structure for the BLM is shown in Fig. 1. The BLM incorporates information from a collection of databases that provide 1) engineering performance data for hundreds of equipment systems, 2) spatially explicit labor cost datasets, and 3) local tax and regulation data. The BLM analytic engine is built in the systems dynamics software package Powersim ${ }^{\mathrm{TM}}$. The BLM is designed to work with thermochemical and biochemical based biofuel conversion platforms and accommodates a range of cellulosic biomass types (i.e., herbaceous residues, short- rotation woody and herbaceous energy crops, woody residues, algae, etc.) $[11,12]$. The BLM simulates the flow of biomass through the entire supply chain, tracking changes in feedstock characteristics (i.e., moisture content, dry matter, ash content, and dry bulk density) as influenced by the unit operations in the supply chain. By accounting for all of the equipment that comes into contact with biomass from the point of harvest to the throat of the conversion facility and the change in characteristics, the BLM evaluates economic performance of the engineered system, as well as determining energy consumption and green house gas performance of the design.

\section{Model Structure}

The BLM is comprised of a series of sub-models to organize calculations and information shown in Fig 2. A graphical user interface allows the navigation from one submodel to the next where individual input screens allow users to adjust model assumptions (i.e., feedstock variety, equipment type, operating parameters etc.) These assumptions greatly impact supply system costs so it is important to be able to easily access and modify these inputs. The BLM uses the SQL data management engine to output calculated data allowing results to be shared and compared using graphs and charts.

The first set of sub-models, tracks the potential locations of biomass throughout the feedstock logistics supply system. Currently, these locations and subsequent sub-models include:

- a biomass production location (i.e., fieldside or stand)

- a primary intermediate location (i.e., depot)

- a secondary intermediate location (i.e., terminal)

- a conversion facility location (i.e., biorefinery, biopower plant, etc.). 


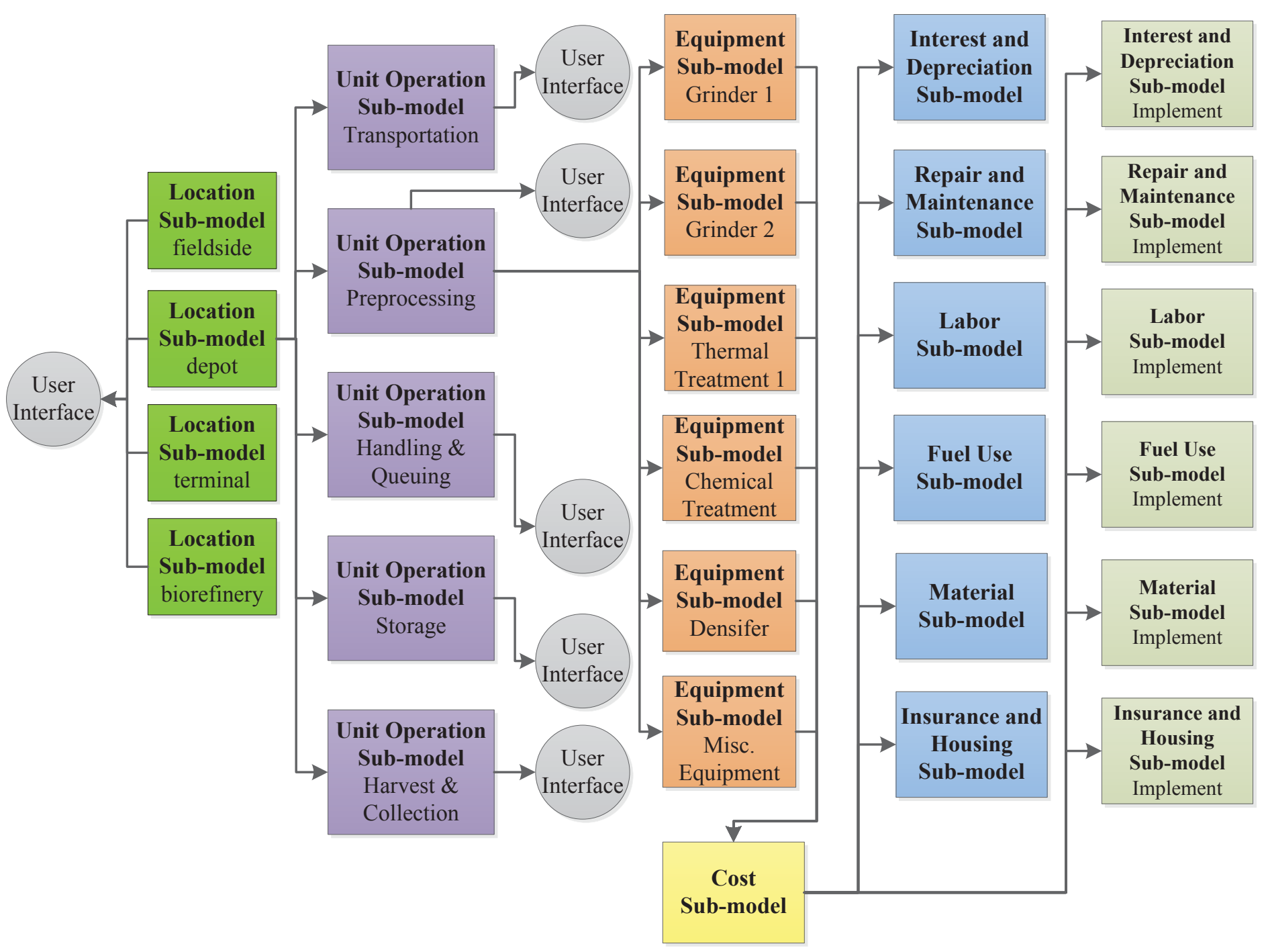

Figure 2. BLM Sub-model Structure.

Using locations as an organization category for the top level of sub-models is an accounting tool to avoid accidental redundancy in logistics system setup.

The next set of sub-models includes the major supply system unit operations: i.e., harvest and collection, storage, transportation, preprocessing, and handling and queuing at the biorefinery. Design decisions for each supply system unit operation impact the engineering design and performance of the other system elements. Because of this it is important to understand each unit operation and its connection with the rest of the system.

Harvest and collection operation encompasses all activities required to gather and remove feedstock from the place of production. The harvest method depends on the specific biomass feedstock variety. For example, an herbaceous feedstock (i.e., corn stover, switchgrass, wheatstraw, etc.) harvest system could include a combine, rake, baler, windrower, and or forage chopper (see Figure 1), while a woody feedstock (i.e., thinnings, slash, pulpwood, etc.) harvest system could include a feller buncher, chainsaw system, or forage harvester. Harvest systems for row crops and perennial crops have a limited temporal window when they can operate each year due to the growth cycles of the crops. This window often changes from year to year due on environmental conditions. A constantly changing harvest window puts significant stress on the harvest and collection operations within the supply system. Collection involves moving harvested biomass to a centralized location, such as a field side stack or a landing deck. Potential collection equipment includes roadsiders, loaders, skidders, and cable systems. Like harvest, collection also only occurs during a specified window where optimal conditions can be achieved to maximize biomass quality and reduce material loss. 
Preprocessing includes any physical or chemical activity that changes the material, such as chipping, grinding, drying, and densification. Preprocessing may also include necessary auxiliary operations, such as dust collection and conveyors. In general, the goal of preprocessing is to increase the quality and uniformity of biomass in order to decrease transportation and handling costs further along the supply chain. For a conventional biomass supply system, the preprocessing operation is generally inside the gate of the conversion facility.

Storage involves stockpiling material to either: (1) provide an adequate lead time to more expensive processes downstream; (2) accumulate appropriate quantities making movement more economical; or (3) minimize the footprint and storage infrastructure at the refinery. Storage is mainly comprised of infrastructure, which can include cement, gravel or asphalt pads, silos, storage bins, and tarps. Since harvest usually occurs during a specified window of time, storage is necessary to maintain an adequate and constant flow of biomass to the conversion facility.

Transportation includes all processes involved in the movement of material from many local locations to a centralized location, such a biorefinery. The distinction between collection and transportation is that collection gathers highly dispersed biomass from a field or stand and moves it to a local location and requires specialized machinery capable of off-road navigation, while transportation takes advantage of existing roadways, railways, and waterways. Transportation includes processes such as loading, trucking, rail transport, and unloading.

Handling and Queuing involves processes required to move biomass material from a local storage location inside the gates at the biorefinery to the throat of the conversion. Surge bins, conveyors, dust collection, and miscellaneous equipment could be included in the Handling and Queuing operation.

With the exception of the Harvest and Collection operation, all location sub-models include all five unit operation sub-models. Harvest and Collection operations are only included in the biomass production sub-model for obvious reasons. Next, within the unit operation sub-models, equipment sub-models organize information specific to each piece of equipment. For example within the preprocessing sub-model, equipment sub-models include: several thermal treatment submodels, grinding sub-models, a densification sub-model, a chemical treatment sub-models, a loader sub-model, and miscellaneous equipment sub-models. For storage, the equipment specific sub-models include; a loader sub-model and a special infrastructure sub-model that involves additionally items like concrete pads, pole-barns, silos, liquid storage, tarping and wrapping. Within these sub-models, relationships based on on-going research connect performance with feedstock characteristics, allowing for a more predictive approach to feedstock supply system design.
Next within the unit operations, parallel to the equipment sub-models are cost sub-models. The cost sub-model encompasses several specific cost-models including:

- labor cost sub-model

- insurance and housing cost sub-model

- interest and depreciation cost sub-model

- repair and maintenance cost sub-model

- fuel use cost sub-model

- material cost sub-model

These specific cost sub-models encompass established and generally accepted equations for calculating cost associated with each activity. For example, energy requirements are calculated in the fuel use cost sub-model, as a function of performance from the horsepower rating of the equipment involved. All costs are expressed in terms of final product in the fuel-use cost specific. Additionally, if a implement and power system operation is used, like in the case of a baler and tractor system, an additional series of cost specific sub-models are used including:

- implement labor cost sub-model

- implement insurance and housing cost-submodel

- implement interest and depreciation cost sub-model

- implement repair and maintenance cost sub-model

- implement fuel use cost sub-model

- implement material cost sub-model

The output of both the power system cost specific submodels and the implement cost system sub-models are combined in the overall cost sub-model to give the combine cost, implement and power system cost for that piece of equipment. If a particular piece of equipment does not utilize an implement, like a self-propelled baler, then the implement cost sub-models do not contribute, only the power system submodel.

Because the BLM is an engineering design tool, the general use case is to setup the required feedstock supply system by selecting the volume and quality characteristics of feedstock required to be delivered to the biorefinery. From these initial assumptions, unit processes are chosen and the required configurations are calculated. For example, the number of machines necessary at each process is determined 
using an assumed operating window for periodic operations, and an annual operating window for continuous processes, like preprocessing then, given a manufacturer specific throughput discounted based on performance factors and on-going research, the number of machines required, percent machine utilization, cost and fuel consumed are calculated.

Finally, the BLM simulates a real supply system, tracking biomass throughout the supply chain. As biomass moves through the system, cost is incurred and value is added to the biomass through quality improvements and location of material. Therefore, material lost further into the system has a higher economic consequence. To capture the loss of value resulting from the material lost, a dry matter loss factor is applied to the cost. This dry matter loss factor compensates for the cost of producing material that is effectively lost, as it cannot be used in the conversion process.

Additionally, some unit operations modify feedstock characteristics (i.e., particle size, moisture content, ash content, bulk density, etc.), and these changes can have a large effect on downstream logistics. For example, an increase in dry matter density can have a significant impact on transportation and handling costs, as these costs can be volume-limited requiring more or less trips to haul a specified amount of biomass. The BLM tracks material format and quality changes throughout the supply chain and incorporates experimental relationships from work performed at INL and partnering research entities whenever possible. As the biomass industry develops, quality specification and material standards for biomass feedstocks and their impact on logistics will be pivotal. Meeting material specifications ensures that conversion processes receive a consistent feedstock with appropriate properties to balance feedstock cost and conversion optimization.

The unique model structure of the BLM allows the sequence of operations and location of these operations to be investigated. For example, some biomass feedstock supply chain designs move preprocessing operations to the front of the supply chain (i.e., field or depot), while conventional designs leave preprocessing until inside the conversion facility gates. These different locations restrict fuel types (i.e., diesel, electricity, waste heat, etc.), as well as some machine capacities and efficiencies and have great impacts on system design and cost.

Finally, the BLM has the capability to perform sensitivity analysis on specific variables. Sensitivity analysis establishes how resistant the calculated cost and energy consumption values are to variable assumptions. Operational characteristics, such as speed, efficiency, and throughput are highly variable and are rarely provided by the manufacturer due to variable field conditions, material characteristics, and operator skills. While experimental data and expert knowledge are used, these assumptions may not be representative of large-scale systems. Testing the model to see how sensitive the final results are to changes in the assumed value is helpful to identifying parameters that have a high impact.

To perform a sensitivity analysis, select parameters are assigned a probability distribution (typically normal and uniform), and a high, low, and average value. Then Monte Carlo sampling methods randomly assign values within the chosen distributions for the select parameters. This is performed 1000 times and the results are compared to test the variability in the final results. Finally, the sensitivity functionality in the BLM is used to generate a variety of figures to illustrate the impact of particular variables, including histograms, tornado diagrams, and spider diagrams. Examples of sensitivity analysis will be shown as a result of the case study discussed below.

\section{RESULTS AND DISCUSSION}

\section{Case Study}

To demonstrate the application of BLM, the following conventional biomass feedstock supply systems scenario was considered. As shown in Fig 3. and Fig 4., corn stover is harvested in Iowa using a combine and is allowed to passively dry in a windrow. After reaching $12 \%$ moisture content, the corn stover is baled. The bales are collected and stacked at the edge of the field until needed by the biorefinery. From the field, the bales are transported to the biorefinery where it is ground then used to produce cellulosic ethanol.

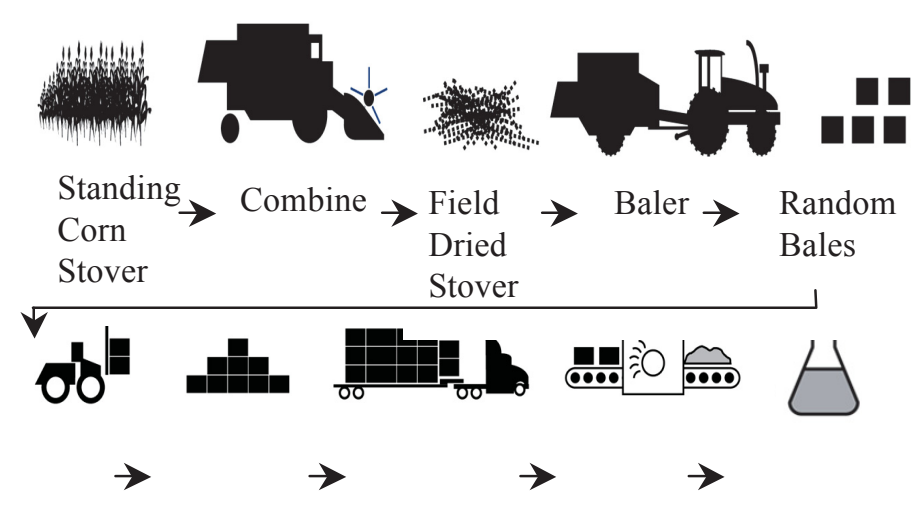

Figure 3. Case Study Conventional Biomass Feedstock Supply Stystem. 


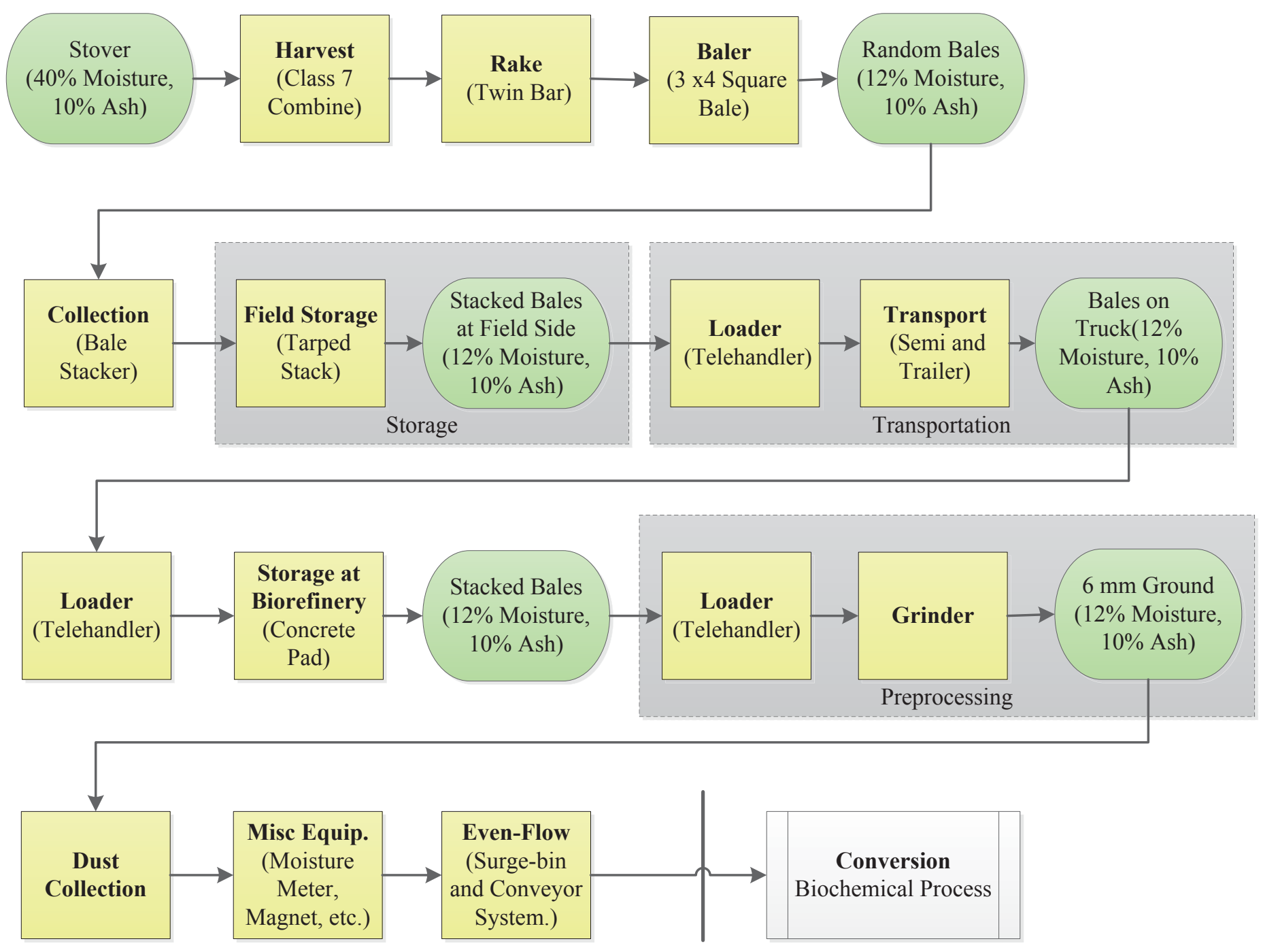

Plant Gate

igure 4. Detailed Case Study Flow Diagram

Given this scenario, a biorefinery could be designed to handle feedstock, however, consider the 2009 and 2010 harvest years below. Figure 5 illustrates the average bale moisture for all corn stover harvested in Iowa for the 2009 and 2010 harvest seasons. While the 2010 harvest averaged bale moistures around $12 \%$, the 2009 harvest averaged bale moistures of about $35 \%$, a difference of $23 \%$ moisture [12]. Using the same scenario as described before, but varying the moisture content from $12 \%$ to $35 \%$, will have substantial impact on the feedstock logistics design as shown by comparing the cost and energy summary for the $12 \%$ and $35 \%$ moisture case. Table 1 and Table 2 summaries these costs and energy consumptions caused by increasing bale moisture and handling more moisture throughout the system. Additional spoilage caused by added moisture was not considered for this study for simplicity.

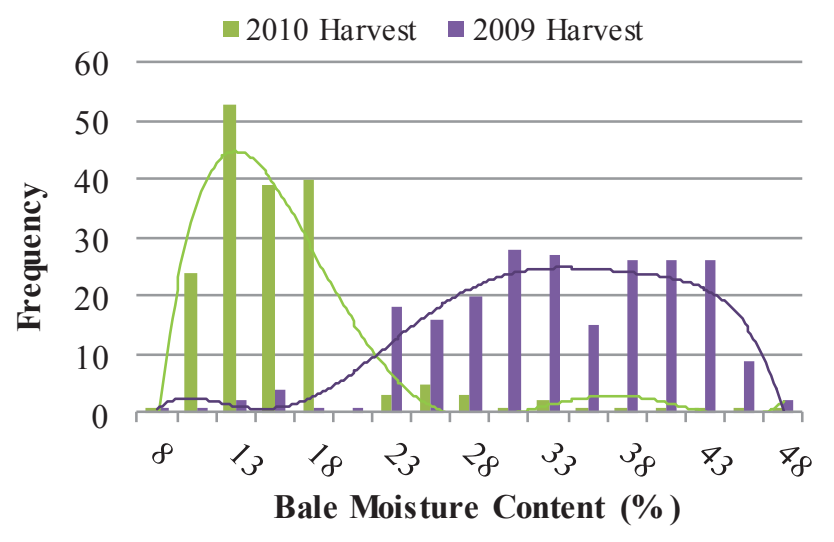

Figure 5: Harvest Moisture 
Table 1. Cost and Energy Consumption for Scenario with $12 \%$ Harvest Moisture.

\begin{tabular}{lcc}
\hline \multicolumn{2}{l}{ Cost and Energy Summary $\left(\right.$ ton $\left.^{-1}, \mathrm{MBTUton}^{-1}\right)$} \\
\hline Operation & $\begin{array}{c}\text { Total Cost } \\
\text { Difference }\end{array}$ & $\begin{array}{c}\text { Energy } \\
\text { Consumed } \\
\text { Difference }\end{array}$ \\
\hline Harvest & 11.97 & 71 \\
Collection & 3.15 & 39 \\
Storage & 1.37 & 13 \\
Transport & 7.36 & 117 \\
Preprocessing & 5.56 & 34 \\
Handling/ & 0.10 & 3 \\
Queuing & & 277 \\
\hline Total & 30.28 & \\
\hline
\end{tabular}

Table 2. Cost and Energy Consumption for Scenario with $35 \%$ Harvest Moisture.

\begin{tabular}{lcc}
\hline \multicolumn{3}{l}{ Cost and Energy Summary $\left(\$\right.$ ton $\left.^{-1}, \mathrm{MBTUton}^{-1}\right)$} \\
\hline Operation & Total Cost & $\begin{array}{c}\text { Energy } \\
\text { Consumed }\end{array}$ \\
\hline Harvest & 12.55 & 71 \\
Collection & 3.15 & 40 \\
Storage & 3.55 & 13 \\
Transport & 8.36 & 134 \\
Preprocessing & 10.55 & 36 \\
Handling/ & 0.10 & 3 \\
Queuing & & 297 \\
\hline Total & 38.26 & \\
\hline
\end{tabular}

Upon inspection of Table 1 and Table 2, increasing bale moisture has an impact on harvest, storage, transportation, and preprocessing costs with an overall cost impact of 8\$/DMton. Preprocessing experiences the greatest cost impact of almost 3\$/DMton.

Next, consider the above scenario, $12 \%$ moisture, but instead of corn stover harvested in Iowa, move to Georgia. Relocating from the "corn belt" has significant consequences to design. For example, crop yields and draw area substantially change moving away from the heavily concentrated and highly productive Midwest. In Georgia, yields are lower than Iowa and density of corn per area is less due to other crops being grown [13]. This variation could also be as a surrogate way to evaluate the influence drought may have on a system as drought usually result in lower yields and less material available due to severe environmental conditions. Table 4 shows the impact a low yield case when compared to the original Iowa scenario case in Table 1. Upon inspection, a lower yield appears to have the most impact on the harvest.

\section{Table 4. Cost and Energy Consumption for Scenario with} lower yield.

\begin{tabular}{lcc}
\hline Cost and Energy Summary $\left(\right.$ Ston $\left.^{-1}, \mathrm{MBTUton}^{-1}\right)$ \\
\hline Operation & Total Cost & $\begin{array}{c}\text { Energy } \\
\text { Consumed }\end{array}$ \\
\hline Harvest & 14.97 & 92 \\
Collection & 4.12 & 45 \\
Storage & 1.37 & 13 \\
Transport & 7.86 & 120 \\
Preprocessing & 5.56 & 34 \\
Handling/ & 0.10 & 3 \\
Queuing & & 307 \\
\hline Total & 33.98 & \\
\hline
\end{tabular}

\section{Sensitivity Analysis}

Finally, if insufficient or unrealistic data is available, sensitivity analysis could also be used to assess feedstock supply system design decisions. For example, fuel prices, the cost of diesel, electricity, and natural gas, are especially hard to predict and historic trends may not realistically encompass all risks in recent markets. Sensitivity analysis can demonstrate possible variances due to changes in these fuel prices. Consider the following variable ranges and distributions shown in Table 6, and the original case study outlined in Fig 3. and Fig 4.

\section{Table 6. Sensitivity Analysis Variables Ranges}

\begin{tabular}{|c|c|c|c|}
\hline Variable & Min & Max & Peak \\
\hline $\begin{array}{l}\text { Electricity } \\
\text { Price }\left(\$ k W h r^{-1}\right)\end{array}$ & 0.04 & 0.12 & 0.06 \\
\hline $\begin{array}{l}\text { On-Road Diesel } \\
\text { Price }\left(\$ \mathrm{gal}^{-1}\right)\end{array}$ & 1.75 & 3.50 & 3.00 \\
\hline $\begin{array}{l}\text { Off-Road Diesel } \\
\text { Price }\left(\$ \mathrm{gal}^{-1}\right)\end{array}$ & 1.50 & 3.25 & 2.75 \\
\hline
\end{tabular}

Given the constraints in Table 6, sensitivity analysis shows that actual cost could vary between 29.40\$/DMton to 38.90 $\$$ /DMton. Figure 6 shows the affect sensitivity analysis has on the total cost of the supply system. Note that the initial feedstock logistics cost, Table 1, was calculated to be 30.28 \$/DMton. 
Total Cost

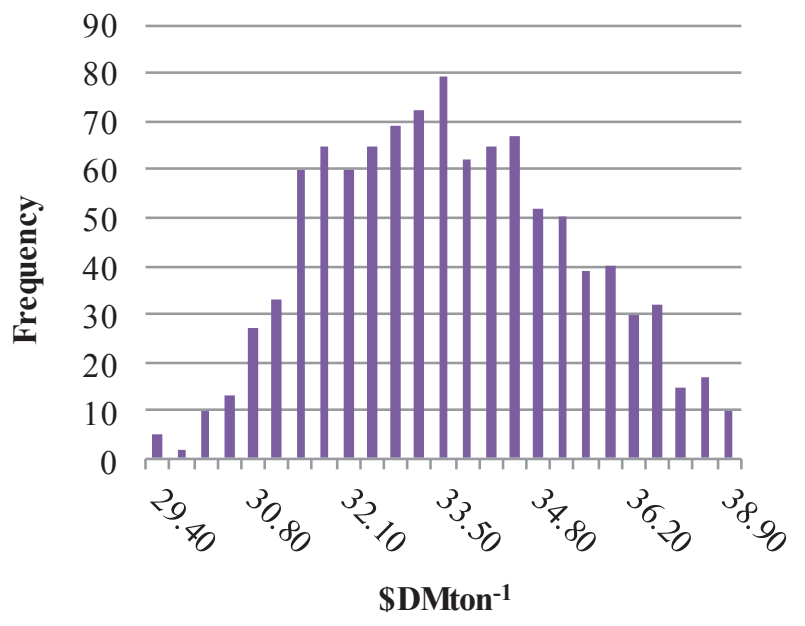

Figure 6. Feedstock Supply Cost Sensitivity Analysis Histogram

\section{CONCLUSIONS}

Quantifying and designing for the uncertainties within a biomass feedstock supply system can have significant impacts on the economic viability of a biorefinery system. Understanding uncontrollable variability, like environmental factors (bale moisture, and crop yield) and their impact to feedstock logistics is necessary in order to build robust supply system designs capable of withstanding a variety of unknowns. This work presented an integrated model called the Biomass Logistics Model that has been developed as a means of exploring potential variances so that once these uncertainties are known; designs can be managed and engineered accordingly. The BLM model was applied to a case study of conventional corn stover feedstock supply system with variances in moisture content, crop yield, and fuel prices. The results suggest that the total cost of corn stover feedstock logistics varied from 29.40 \$/DMton to 38.90 \$/DMton depending on the variable constraints. Understanding the variability in cost based on unpredictable parameters allows more robust designs to be developed.

\section{ACKNOWLEDGMENTS}

This submitted manuscript was authored by a contractor of the U.S. Government under DOE Contract No. DE-AC0705ID14517. Accordingly, the U.S. Government retains and the publisher, by accepting the article for publication, acknowledges that the U.S. Government retains a nonexclusive, paid-up, irrevocable, worldwide license to publish or reproduce the published form of this manuscript, or allow others to do so, for U.S. Government purposes.

\section{REFERENCES}

[1] Fales S.L., Hess J.R., and Wilhelm W.W., 2007, "Convergence of Agriculture and Energy II: Producing Cellulosic Biomass for Biofuels," CAST Commentary QTA2007-2, The Council for Agricultural Science and Technology.

[2] Perlack R.D, and Stokes B.J, "Billion-Ton Update: Biomass Supply For a Bioenergy and Bioproducts Industry," Technical Report No. ORNL/TM-2011/224. Oak Ridge National Laboratory, Oak Ridge, TN.

[3] Hess J.R., Kenney K., Ovard L., Searcy E., and Wright C., 2009, "Uniform-Format Bioenergy Feedstock Supply System Design Report: Commodity-Scale Production of an Infrastructure-Compatible Bulk Solid From Herbaceous Lignocellulosic Biomass," Technical Report No. INL/EXT-08-14752. Idaho National Laboratory, Idaho Falls, ID.

[4] BTAC (Biomass Technical Advisory Committee), 2007, "Vision for Bioenergy and Biobased Products in the United States", Energy Independence and Security Act of 2007.

[5] Cundiff, J.S., Dias,N., and Sherali, H.D, 1997, “A Linear Programming Approach for Desiging A Herbaceous Biomass Delivery System," Bioresource Technology, 59(1), pp 47-55.

[6] Mapemba, L.D., Epplin, F.M., Hunhke, R.L., and Taliaferro, C.M., 2008, "Herbaceous Plant Biomass Harvest and Devlivery Cost with Harvest Segmented by Month and Number of Harvest Machines Endogenously Determined,"Biomass and Bioenergy, 32, pp 1016-1027.

[7] Shastri,Y., Hansen, H., Rodriguez, L., and Ting, K..C., 2011, "Development and Application of BioFeed Model for Optimization of Herbaceous Biomass Feedstock Production," Biomass and Bioenergy, 35(7), pp29612974.

[8] Sokhansonj, S., Kumar, A., and Turhollow, A.F., 2006, "Development and Implementation of Integrated Biomass Supply Analysis and Logistics Model (IBSAL)," Biomass and Bioenergy, 30(10), pp 838-847.

[9] Sokhansonj, S., and Kumar, A., 2007,'Switchgrass (Panicum vigratum,,L.) Delivery to a Biorefinery Using Integrated Biomass Supply Analysis and Logistics (IBSAL) Model,"Bioresource Technology, 98, pp 10331044.

[10] Cook, D.E., and Shinners, K..J., 2011, "Economics of Alternative Corn Stover Logistics Systems,"ASABE Paper No. 1111130.

[11] Searcy, E., and Hess, J. R., 2010, "Uniform-Format Feedstock Supply System Design Reports: A 
Commodity-Scale Design to Produce an InfrastructureCompatible Biocrude from Lignocellulosic Biomass"

Technical Report No. INL/EXT- 10-20372. Idaho

National Laboratory, Idaho Falls, ID.

[12] Tumuluru, J.S.,Wright C.T., Hess, J.R., and Kenney K.L., 2011, A Review Of Biomass Densification Systems to Develop Uniform Feedstock Commodities for Bioenergy Application", Biofuels, Bioproducts, and Biorefining, 5(6) pp 683-707.

[13] Smith,W.A, 2013, Personal Communication. Idaho National Laboratory, Idaho Falls, ID.

[14] National Agricultural Statistics Service, 2011,"Corn Grain 2011 Yield Per Harvested Acre By County for Selected States," U.S. Department of Agriculture, http://.nass.usda.gov/Charts_maps/Crops/County. 